\title{
Regulation of the PTEN/PI3K/AKT pathway in RCC using the active compounds of natural products in vitro
}

\author{
XUE WANG $^{1,2}$, ZHENHUA XIE $^{1}$, ZHONGGUAN LOU $^{1}$, YULU CHEN ${ }^{1,3}$, \\ SHUAISHUAI HUANG ${ }^{1}$, YU REN ${ }^{1}$, GUOBIN WENG ${ }^{1}$ and SHUWEI ZHANG ${ }^{1}$
}

${ }^{1}$ Urology and Nephrology Institute of Ningbo University, Ningbo Urology and Nephrology Hospital, Ningbo, Zhejiang 315000; ${ }^{2}$ Zhejiang Key Laboratory of Pathophysiology, School of Medicine, Ningbo University, Ningbo, Zhejiang 315211;

${ }^{3}$ Department of Stomatology, Ningbo Urology and Nephrology Hospital, Ningbo, Zhejiang 315000, P.R. China

Received May 21, 2021; Accepted August 3, 2021

DOI: $10.3892 / \mathrm{mmr} .2021 .12406$

\begin{abstract}
Since Professor Tu Youyou won the 2015 Nobel Prize in Physiology and Medicine for the discovery of artemisinin, which is used to treat malaria, increased attention has been paid to the extracts obtained from plants, in order to analyze their biological activities, particularly with regard to their antitumor activity. Therefore, the present study explored the biochemical properties of seven natural plant extracts on renal cell carcinoma (RCC). 786-O and OS-RC-2 cells were cultured and treated with different concentrations of the extracts. Then, cell viability, the $\mathrm{IC}_{50}$ value and proliferation was determined using a Cell Counting Kit- 8 assay. Apoptosis and cell cycle distribution were evaluated via flow cytometry. The expression levels of proteins were assessed using western blotting, and cellular morphology was observed using a light microscope. The results showed that sophoricoside, aucubin, notoginsenoside R1 and ginsenoside Rg1 did not exhibit a cytotoxic effect on RCC cells, whereas ginsenoside Re and allicin exhibited a very slight inhibitory effect. Naringenin possessed the highest activity of the analyzed extracts. The $\mathrm{IC}_{50}$ values of naringenin on $786-\mathrm{O}$ and OS-RC-2 cells were $8.91 \pm 0.33$ and $7.78 \pm 2.65 \mu \mathrm{M}$, respectively. In addition, naringenin notably inhibited the proliferation of RCC cells by decreasing Ki67 expression, blocked cell cycle progression in the $G_{2}$ phase by regulating expression of cell cycle proteins, and increased apoptosis by upregulating caspase- 8 expression, downregulating $\mathrm{Bcl}-2$ expression and altering the cellular morphology. Furthermore, naringenin inhibited cell proliferation and promoted apoptosis by upregulating the expression of PTEN at the protein level, downregulated the
\end{abstract}

Correspondence to: Professor Shuwei Zhang, Urology and Nephrology Institute of Ningbo University, Ningbo Urology and Nephrology Hospital, 998 Qianhe Road, Yinzhou, Ningbo, Zhejiang 315000, P.R. China

E-mail: nbuurology@126.com

Key words: natural products, renal cell carcinoma, proliferation, apoptosis, PTEN/PI3K/p-AKT pathway expression of PI3K and phosphorylated-(p-)AKT, but did not affect the expression of AKT, mTOR or p-mTOR. The seven plant extracts analyzed showed differing degrees of anti-RCC activity. Sophoricoside, aucubin, notoginsenoside R1 and ginsenoside $\operatorname{Rg} 1$ did not exhibit notable anti-RCC activity, whereas the effect of ginsenoside Re and allicin on RCC was considerably weak. However, naringenin showed potent anti-proliferative, apoptosis inducing and cell cycle arresting activity on RCC cells via regulation of the PTEN/PI3K/AKT signaling pathway.

\section{Introduction}

Renal cancer has a high rate of incidence and mortality worldwide (1), and is the second most common cause of deaths amongst urinary system cancers in men and women (2). Renal cell carcinoma (RCC) develops from renal tubules and accounts for $\sim 85 \%$ of all renal cancers, and certain studies have demonstrated that the incidence of RCC has increased by $2-4 \%$ per year over the past decades worldwide (3). However, unlike other solid tumors, standard cytotoxic chemotherapy is still ineffective for RCC, and eventually, most patients develop resistance after receiving one or more therapeutic agents $(4,5)$. Thus, to decrease the death rate associated with RCC, there is a need to develop novel antitumor drugs, and natural compounds serve as a source of potential active compounds.

Several thousand years ago, natural products were used for their medicinal properties (6), and increasing evidence has shown that natural products from vegetables, fruits and traditional medicines for anti-cancer research remains an important source of potentially novel treatments (7-11). Although there was a shift towards the study of synthetic drugs based on molecular biology and combinatorial chemistry, these synthetic drugs have the disadvantages of occasional intolerable side effects and expensive prices $(12,13)$. By comparison, treatment with natural products have fewer side effects, whilst exhibiting favorable outcomes (13). However, to the best of our knowledge, there are no wide-scale investigations on the therapeutic activities of natural products on RCC. Hence, it is valuable to study the effects of compounds in natural products on RCC.

The aberrant activity of multiple molecular signaling pathways are closely related to the development and maintenance of 
cancer $(14,15)$. Amongst these pathways, the PI3K/AKT/mTOR has been identified as important in the regulation of tumor cell proliferation, survival and angiogenesis in cancer (7). However, the role of these pathways is rarely studied with regard to the anti-RCC effect of certain natural products.

In the present study, the ability of several natural products derived from bioactive plants compounds was assessed with regard to their anti-RCC effects, as well as their ability to modulate the PI3K/AKT/mTOR signaling pathways.

\section{Materials and methods}

Cell culture and drug treatment. The 786-O cell line was obtained from the American Type Culture Collection and the OS-RC-2 cell line was purchased from The Cell Bank of Type Culture Collection of The Chinese Academy of Sciences. All cells were cultured in RPMI-1640 (HyClone; Cytiva) medium containing $10 \%$ FBS (Shanghai ExCell Biology, Inc.) at $37^{\circ} \mathrm{C}$ with $5 \% \mathrm{CO}_{2}$ in a humidified incubator.

In total, seven natural products were purchased from Beijing Solarbio Science \& Technology Co., Ltd.: Sophoricoside (cat. no. SS8650); aucubin (cat. no. SA9840); notoginsenoside R1 (cat. no. SN8230); ginsenoside Re (cat. no. SG8310); ginsenoside Rg1 (cat. no. SG8330); naringenin (cat. no. SN8020); and allicin (cat. no. SA8720). According to the manufacturer's instructions, sophoricoside, aucubin and notoginsenoside R1 were dissolved in DMSO, ginsenoside Re and ginsenoside Rg1 were dissolved in $\mathrm{ddH}_{2} \mathrm{O}$, and naringenin and allicin were dissolved in absolute ethanol. All natural products were stored at $4^{\circ} \mathrm{C}$ in the dark and added to cells that had been cultured for $24 \mathrm{~h}$.

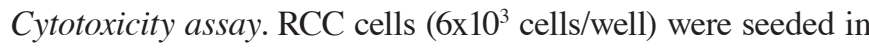
96-well culture plates for $24 \mathrm{~h}$, and then treated with the indicated compounds at various concentrations for 48 h; see Fig. 1 for details of treatments. According to the manufacturer's instructions, cell cytotoxicity was detected by treating cells with $10 \mu \mathrm{l}$ Cell Counting Kit-8 (CCK-8; cat. no. CK04; Dojindo Molecular Technologies, Inc.) at $37^{\circ} \mathrm{C}$ for $2-4 \mathrm{~h}$. Subsequently, the absorbance was measured on a Thermo Multiskan spectrophotometer (Thermo Fisher Scientific, Inc.) at a wavelength of $450 \mathrm{~nm}$.

Subsequently, the RCC cells were treated with different concentrations of naringenin $(0,1,2,4,6,8,10,12,14$ or $16 \mu \mathrm{m})$ or allicin $(0,100,200,300,400,500,600,700,800$ or $900 \mu \mathrm{m}$ ) for $48 \mathrm{~h}$, and then, as described above, the cells were incubated with the CCK- 8 solution. The $\mathrm{IC}_{50}$ of naringenin and allicin for each cell line was calculated using SPSS version 13.0 (SPSS, Inc.).

Cell proliferation assay. RCC cells were cultured with naringenin $(0,4$ or $8 \mu \mathrm{m})$ for different periods of time $(0,24,48,72$ or $96 \mathrm{~h}$ ), or, after pretreatment with a PTEN inhibitor (SF1670, MedChemExpress)/activator (Oroxin B, MedChemExpress) for $24 \mathrm{~h}$ in a $37^{\circ} \mathrm{C} \mathrm{CO}_{2}$ incubator, cells were treated with $4 \mu \mathrm{m}$ naringenin for $24 \mathrm{~h}$. Subsequently, cells were incubated with $10 \mu \mathrm{l} \mathrm{CCK}-8$ at $37^{\circ} \mathrm{C}$ for $2-4 \mathrm{~h}$. Finally, cell proliferation was determined by measurement of the absorbance at $450 \mathrm{~nm}$ on a spectrophotometer.

Cell apoptosis analysis. An Annexin V binding assay was employed to detect apoptosis using an Annexin V-FITC and
PI staining kit (cat. no. AP101-30; MultiSciences Biotech Co., Ltd.) according to the manufacturer's protocols. Briefly, the RCC cells were seeded in 6-well cell plates for $24 \mathrm{~h}$ and then RCC cells were treated as described above for the cell proliferation assay. The treated cells were stained with $500 \mu \mathrm{l}$ $1 \mathrm{X}$ Binding Buffer containing $5 \mu \mathrm{l}$ Annexin V-FITC and $10 \mu \mathrm{l}$ PI for $5 \mathrm{~min}$ in the dark. The percentage of apoptotic cells were measured using a CytoFLEX LX flow cytometer (Beckman Coulter, Inc.). Early + late apoptosis rates were assessed using CytExpert version 2.3.0.84 (Beckman Coulter, Inc.).

Cell cycle assays. 786-O and OS-RC-2 cells were treated as described above for the cell proliferation assays. Subsequently, cells (2-10x10 cells/well) were digested and washed. According to the manufacturer's protocol of the cell cycle detection kit (cat. no. CCS012; MultiSciences Biotech Co., Ltd.), the cells were incubated in $1 \mathrm{ml}$ DNA staining solution containing $10 \mu \mathrm{l}$ permeabilization solution (from the kit) for $30 \mathrm{~min}$ at room temperature. Finally, analysis of cell cycle distribution was performed using a CytoFLEX LX flow cytometer (Beckman Coulter, Inc.) and cell cycle was analyzed using DNA Modeling Software (Modfit LT 3.2, version number. 3.1.0.0).

Morphological examination. The 786-O and OS-RC-2 cells were cultured in 6-well plates. After overnight incubation to allow adherence, the RCC cells were treated with the designated concentrations ( 0 and $8 \mu \mathrm{M}$ naringenin) for $48 \mathrm{~h}$ at $37^{\circ} \mathrm{C}$ in carbon dioxide cell incubator. The features of mitotically arrested cells were bright, rounded and could be easily detached from the bottom of the plate. The cell morphology was detected and images were captured using a fluorescence inverted microscope (magnification, x400; Motic AE31; Motic Incorporation, Ltd.) (16).

Western blotting. As described above, the RCC cells were treated with naringenin in 6-well plates. Protein was extracted using High-efficiency RIPA lysis buffer (Beijing Solarbio Science \& Technology Co., Ltd.). Protein concentration was determined using a BCA protein assay kit (Beyotime Institute of Biotechnology), according to the manufacturer's instructions. Subsequently, equal amounts of protein $(20 \mu \mathrm{g})$ were resolved on a $10-12 \%$ SDS-PAGE gel and subsequently transferred to PVDF membranes at $200 \mathrm{~mA}$ for $120 \mathrm{~min}$. Following this, the membrane was blocked with $5 \%(\mathrm{w} / \mathrm{v})$ non-fat dry milk for $2 \mathrm{~h}$ at room temperature. After washing the membranes with TBS with $0.1 \%$ Tween-20 (TBST), they were incubated with the following primary antibodies: Anti-minichromosome maintenance complex component 2 (MCM2; cat. no. 12079), anti-PI3K (cat. no. 4249), anti-AKT (cat. no. 4685), anti-p-AKT (cat. no. 13038), anti-cyclin E1 (cat. no. 20808), anti-Bcl-2 (cat. no. 15071), anti-Bax (cat. no. 5023), anti-phosphorylated (p-)mTOR (cat. no. 5536), anti-caspase-9 (cat. no. 9502), anti-caspase-3 (cat. no. 14220), anti-GAPDH (cat. no. 5174) and anti- $\beta$-actin (cat. no. 8457) (all from Cell Signaling Technology, Inc.), anti-cyclin B1 (cat no. AF6168), anti-cyclin A2 (cat. no. AF0142), anti-P21 (cat. no. AF6290), anti-P27 (cat. no. AF6324), anti-mTOR (cat. no. AF7803), anti-PTEN (cat. no. AF6351) (all from Affinity Biosciences, Ltd.), anti-ki67 (cat. no. ab16667), anti-caspase-8, (cat. no. ab25901; all from Abcam) and anti-cyclin D1 (cat. no. PB0403; Wuhan Boster 

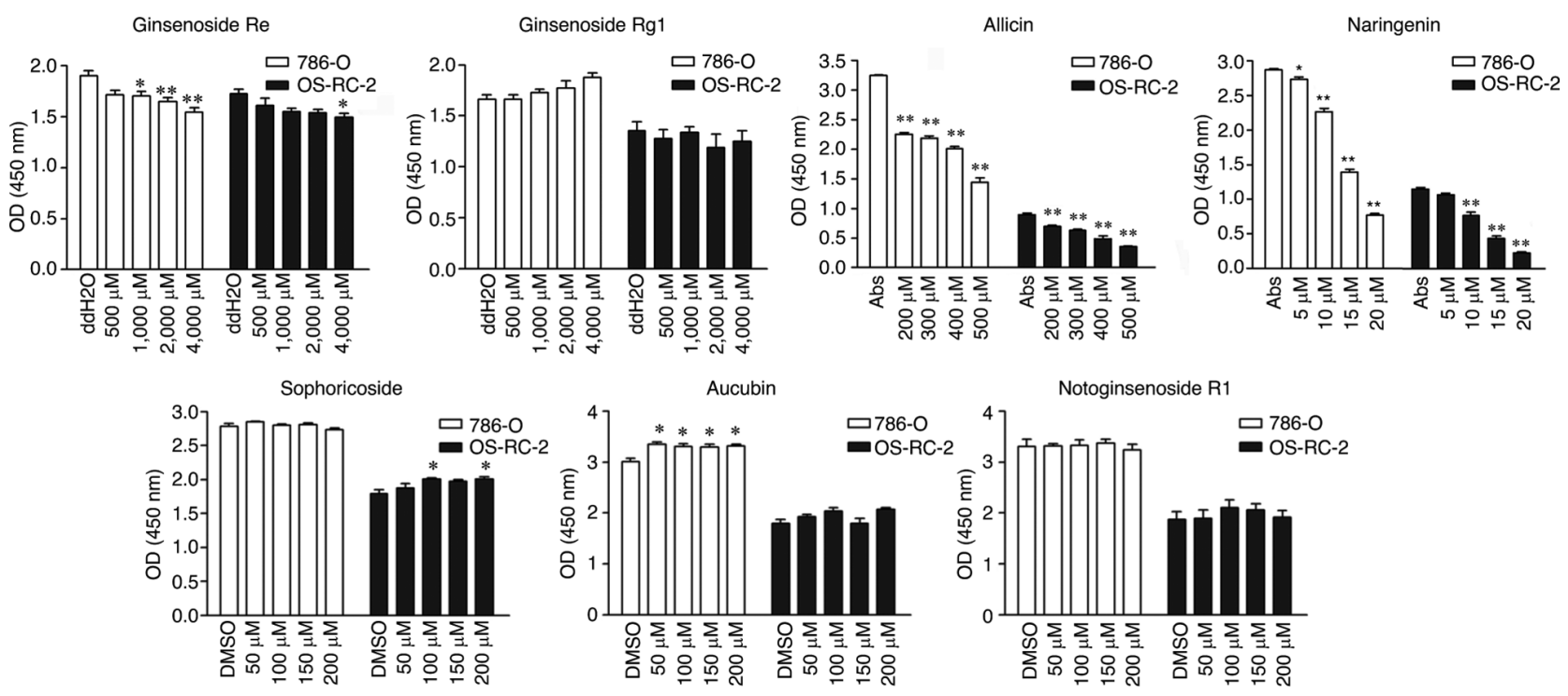

Figure 1. Cytotoxic effects of the seven natural products on 786-O and OS-RC-2 cells. Cells were treated for 48 h with sophoricoside, aucubin, notoginsenoside R1, ginsenoside Re, ginsenoside Rg1, naringenin or allicin. Cytotoxicity was measured using a Cell Counting Kit-8 assay. Data are presented as the mean \pm SD. ${ }^{*} \mathrm{P}<0.05,{ }^{* *} \mathrm{P}<0.01$ vs. $\mathrm{ddH}_{2} \mathrm{O}$, Abs or DMSO. Abs, absolute ethanol.

Biological Technology Ltd.) overnight at $4^{\circ} \mathrm{C}$. All primary antibodies were used at a dilution of 1:1,000. After washing four times with TBST, membranes were incubated with secondary goat anti-mouse (cat. no. BA1050) or anti-rabbit antibodies (cat. no. BA1054; 1:5,000; both purchased from Wuhan Boster Biological Technology, Ltd.) for $2 \mathrm{~h}$ at room temperature. Finally, signals were visualized using a K-12045-D10 ECL system (Advansta, Inc.). The semi-quantification analysis was performed by Tanon GIS version 4.1.2 software (Tanon Science and Technology Co., Ltd.).

Statistical analysis. All data are expressed as the mean \pm SD of three independent experiments and were analyzed using SPSS version 13.0 (SPSS, Inc.). One-way ANOVA with a post hoc Bonferroni test was used for multiple comparisons. $\mathrm{P}<0.05$ was considered to indicate a statistically significant difference.

\section{Results}

Cytotoxic effects of the seven natural plant compounds on RCC cells. To determine the cytotoxic effects of the seven natural plant compounds against two RCC cell lines, 786-O and OS-RC-2, a CCK-8 assay was conducted. The results revealed an association and species-dependent cytotoxic effect of the examined plant compounds ginsenoside Re, naringenin and allicin. However, whilst ginsenoside Re exhibited anti-RCC activity, this effect was weak; the $\mathrm{IC}_{50}$ values of allicin were $469.10 \pm 42.35$ and $353.40 \pm 18.59 \mu \mathrm{M}$ in $786-\mathrm{O}$ and OS-RC-2 cells, respectively. The $\mathrm{IC}_{50}$ values of 786-O and OS-RC-2 cells treated with naringenin were $8.91 \pm 0.33$ and $7.78 \pm 2.65 \mu \mathrm{M}$, respectively. The four other compounds did not show significant cytotoxic effects (Fig. 1). Therefore, it was determined that naringenin had the most potent cytotoxic effect, and was thus studied further.

Naringenin inhibits the proliferation of 786-O and $O S-R C-2$ cells. Fig. 2A shows the chemical structure of naringenin. The effect of naringenin on proliferation in RCC cells was next assessed. As shown in Fig. 2B and C, naringenin significantly inhibited RCC cell proliferation. The expression of Ki67 and MCM2 were assessed, and the results showed that naringenin inhibited Ki67 expression with little to no effect on MCM2 expression (Fig. 2D). Therefore, it was suggested that naringenin inhibited RCC cell proliferation by decreasing Ki67 expression.

Naringenin induces $G_{2}$ phase cell cycle arrest in 786-O and $O S-R C-2$ cells. Naringenin significantly increased the proportion of cells in the $\mathrm{G}_{2}$ phase in the two RCC cell lines (Fig. 3A). At the same time, naringenin reduced cyclin A2, cyclin B1 and cyclin D1 protein expression levels, whilst promoting cyclin E1 and P21 protein expression levels, with no effect on P27 protein expression levels (Fig. 3B). Therefore, it was suggested that naringenin blocked cell cycle progression in the $\mathrm{G}_{2}$ phase, and the means by which it inhibited RCC proliferation was by regulating the expression of cell cycle proteins.

Naringenin and honokiol induce apoptosis of RCC cells. Induction of cytotoxicity is also associated with the ability to induce the apoptosis of cancer cells (17). To further determine whether naringenin induced apoptosis, morphological analysis was performed using a light microscope. As shown in Fig. 4A, naringenin induced cell apoptosis in 786-O and OS-RC-2 cells, and notable changes in cellular morphology in both cell lines were observed. The cell body became rounded, shrunken and blebbed, and some cells became elongated and dissolved. Quantification of apoptosis was performed using an Annexin V-FITC/PI apoptosis detection kit. The proportion of apoptotic RCC cells was significantly increased after treatment with 4 and $8 \mu \mathrm{m}$ naringenin for $48 \mathrm{~h}$ (Fig. 4B). The expression of apoptosis-related proteins was next assessed. In both cell lines, naringenin decreased Bcl-2 and caspase-3 expression, increased caspase- 8 and cleaved-caspase-9 (35 kDa) expression, and had little effect on cleaved-caspase-3, caspase-9, 
A

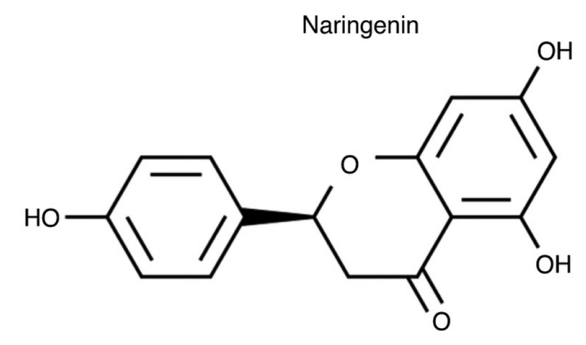

C

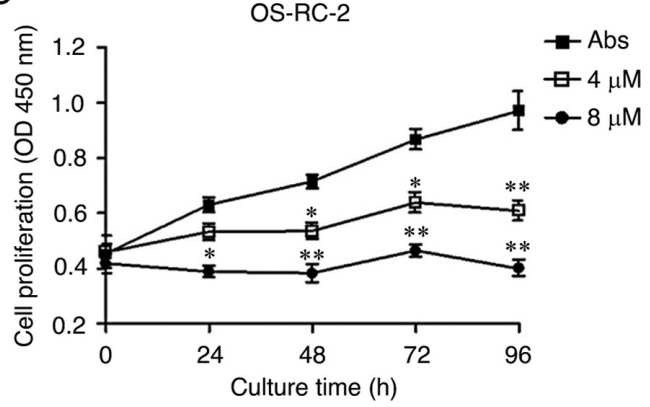

$\mathrm{B}$

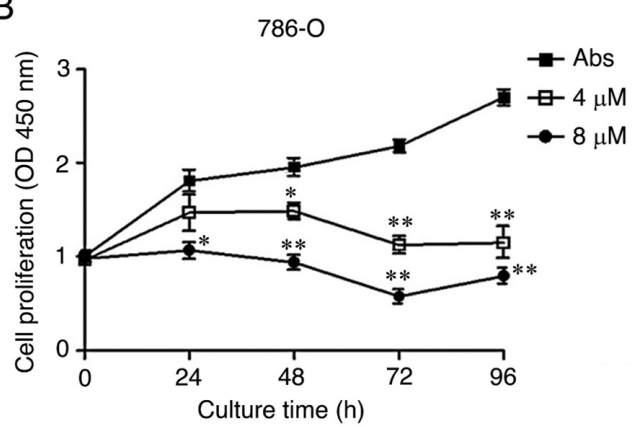

$\mathrm{D}$

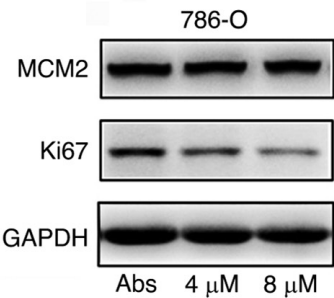

OS-RC-2

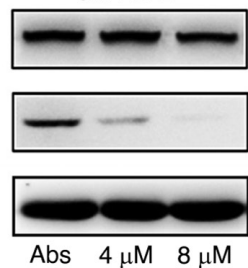

Figure 2. Naringenin inhibits proliferation of renal cell carcinoma cells. (A) Chemical structure of naringenin. (B) 786-O and (C) OS-RC-2 cells were incubated with naringenin at different concentrations $(0,4$ or $8 \mu \mathrm{M})$ at different time-points $(0,24,48,72$ and $96 \mathrm{~h})$. Cell proliferation was measured using Cell Counting Kit-8 assays. (D) Western blot analysis of MCM2 and Ki67 expression levels. Data are presented as the mean \pm SD. ${ }^{*} \mathrm{P}<0.05,{ }^{* *} \mathrm{P}<0.01$ vs. Abs. Abs, absolute ethanol; MCM2, minichromosome maintenance complex component 2.

A
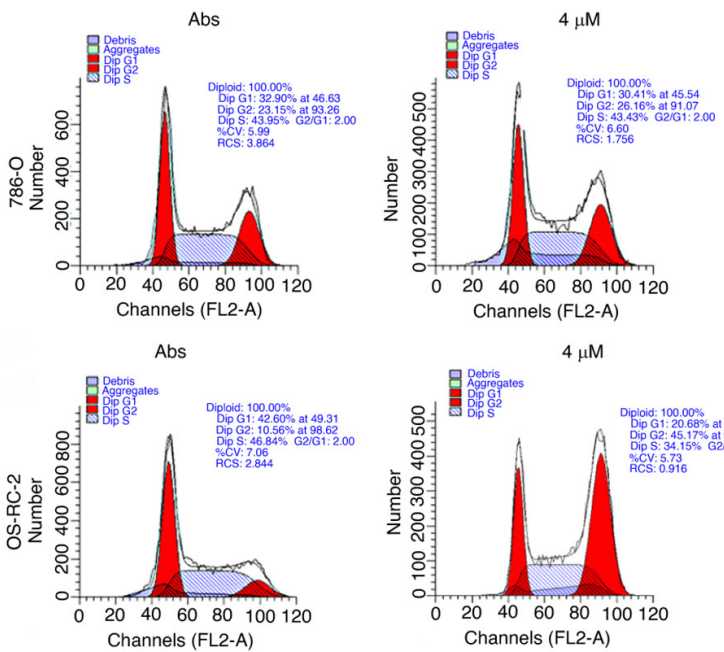
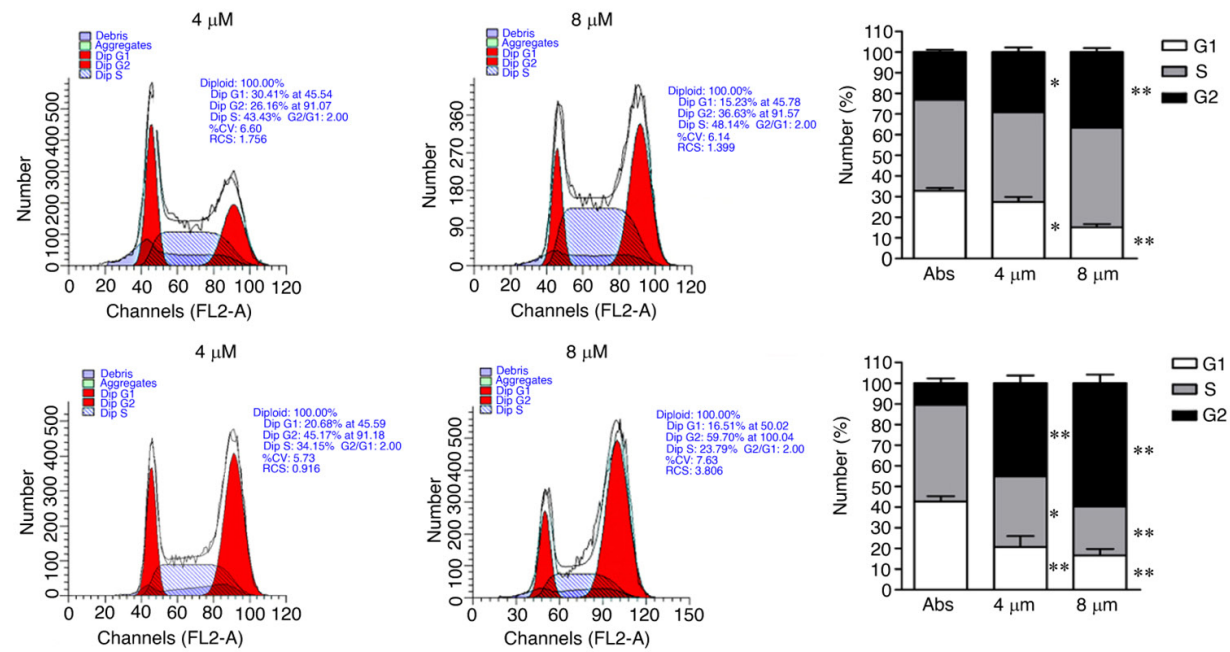
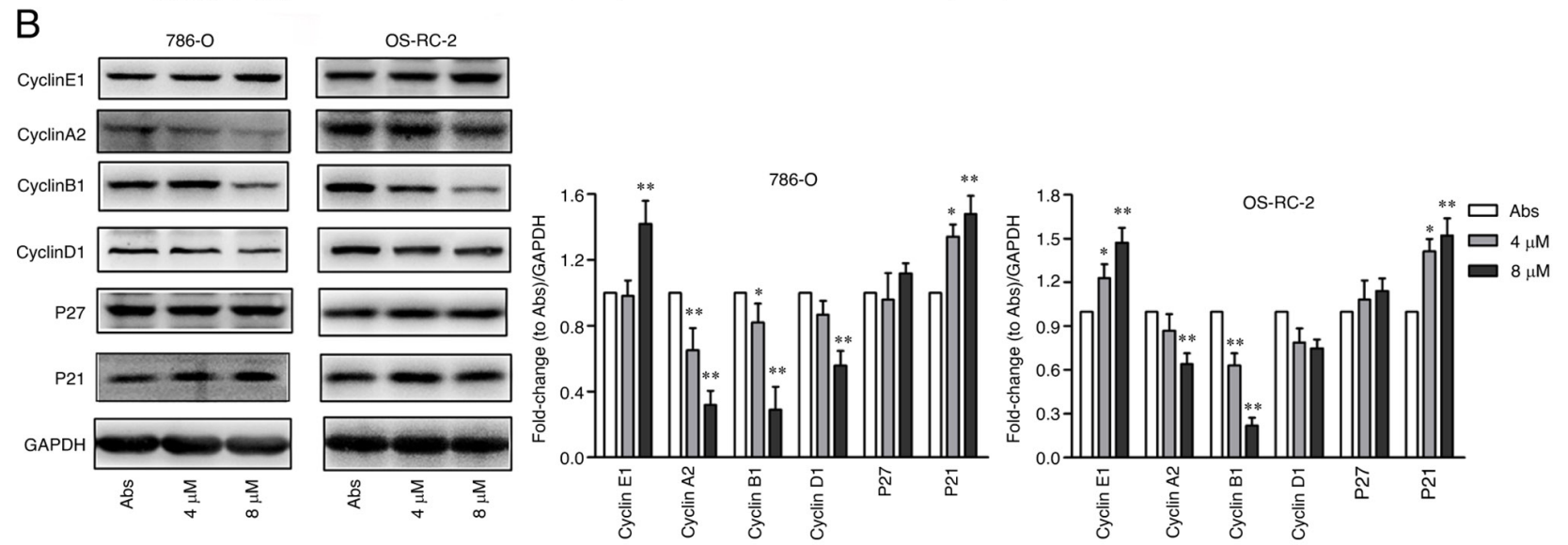

Figure 3. Naringenin arrests cell cycle progression of renal cell carcinoma cells in the $\mathrm{G}_{2}$ phase. $786-\mathrm{O}$ and $\mathrm{OS}-\mathrm{RC}-2$ cells were treated with naringenin $(0,4$ or $8 \mu \mathrm{M}$ ) for $48 \mathrm{~h}$. (A) Cell cycle distribution was determined using flow cytometry. (B) Western blot analysis of cyclin E1, cyclin A2, cyclin B1, cyclin D1, P27 and $\mathrm{P} 21$ expression levels. Data are presented as the mean $\pm \mathrm{SD} .{ }^{*} \mathrm{P}<0.05,{ }^{* *} \mathrm{P}<0.01$ vs. Abs. Abs, absolute ethanol. 
A
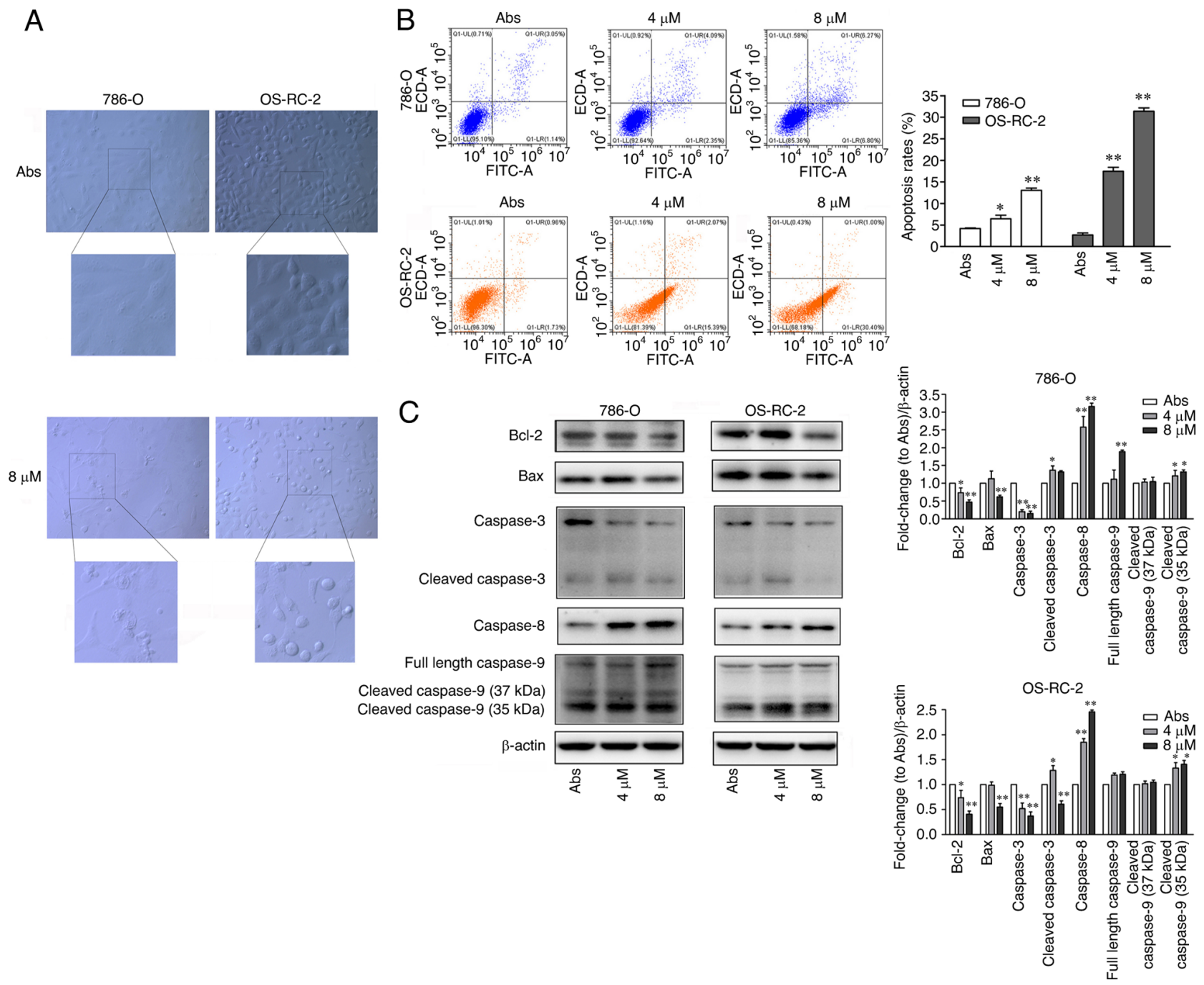

Figure 4. Naringenin induces apoptosis in RCC cells. (A) Morphological analysis of apoptotic cells. Bright field images of 786-O and OS-RC-2 cells treated with naringenin $(0$ or $8 \mu \mathrm{M})$. Magnification, $\mathrm{x} 400$. (B) 786-O and OS-RC-2 cells were treated with different concentrations of naringenin for $48 \mathrm{~h}$. Flow cytometry analysis demonstrated that naringenin increased apoptosis in a dose-dependent manner. (C) Western blotting analysis of Bcl-2, Bax, caspase-3, caspase- 8 and caspase-9 levels in treated RCC cells. Data are presented as the mean $\pm \mathrm{SD}$. ${ }^{*} \mathrm{P}<0.05,{ }^{* *} \mathrm{P}<0.01 \mathrm{vs}$. Abs. Abs, absolute ethanol; RCC, renal cell carcinoma.

cleaved-caspase-9 (37 kDa) and Bax protein expression (Fig. 4C). These results demonstrated that naringenin significantly increased the apoptosis of the two RCC cell lines by upregulating the expression of apoptosis-related proteins.

Naringenin inhibits the PTEN/PI3K/p-AKT signaling pathway in RCC cells. Next, the molecular mechanisms involved in the naringenin-induced effects were assessed. As shown in Fig. 5, naringenin treatment upregulated the expression of PTEN, downregulated the expression of PI3K and p-AKT protein, and had no notable effects on AKT, mTOR and p-mTOR expression. Naringenin may thus inhibit RCC progression by inhibiting the PTEN/PI3K/AKT axis.

Inhibition of PTEN expression attenuates the effects of naringenin. Cells were pre-treated with a PTEN inhibitor (SF1670), and then treated with $4 \mu \mathrm{m}$ naringenin for $24 \mathrm{~h}$. Subsequently, cell proliferation, apoptosis and the protein expression levels of PTEN, PI3K, AKT and p-AKT were determined. Following treatment with SF1670, RCC cell proliferation was increased (Fig. 6A) and apoptosis was decreased compared with naringenin alone (Fig. 6B). Additionally, the expression of PTEN was decreased, the expression levels of PI3K and p-AKT were increased, whilst the expression of AKT was not notably altered compared with the cells treated with naringenin alone (Fig. 6C). These data suggested that PTEN inhibition attenuated the growth inhibitory effects of naringenin via activation of the PI3K/AKT signaling pathway.

Activation of the PTEN expression augments the effects of naringenin. RCC cells were next treated with a PTEN activator (Oroxin B), and subsequently treated with naringenin. The results of the CCK-8 (Fig. 7A) and cell apoptosis (Fig. 7B) assays showed that the naringenin-induced decrease in proliferation and increase in apoptosis were slightly strengthened after treatment with Oroxin B, and the expression of PTEN was increased, whereas those of PI3K and p-AKT were decreased, compared with the group treated with naringenin alone (Fig. 7C). These data indicated that activation of PTEN potentiates the cytotoxic effects of naringenin by inhibiting the PI3K/AKT signaling pathway. 

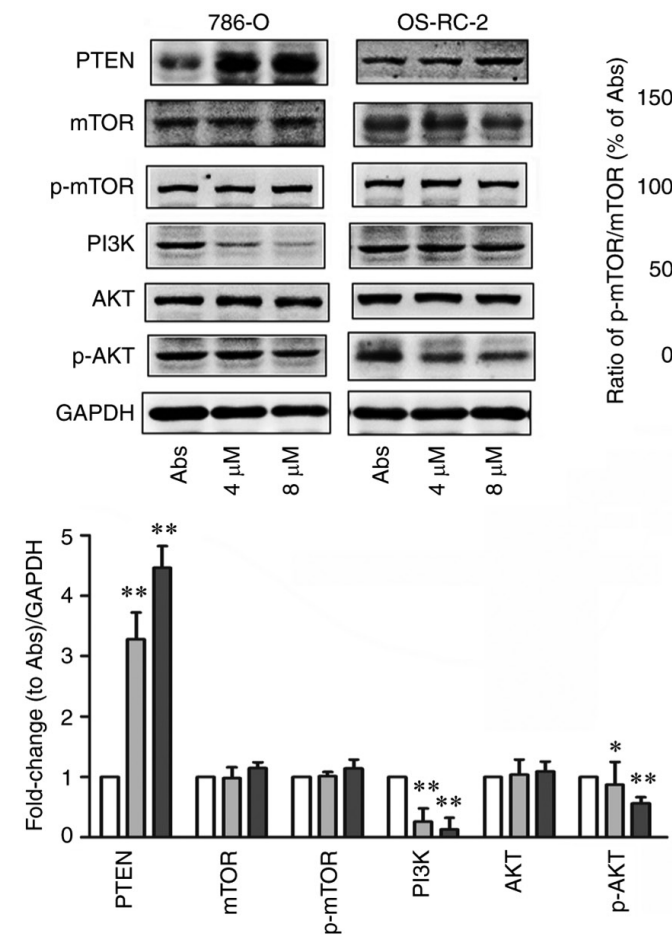
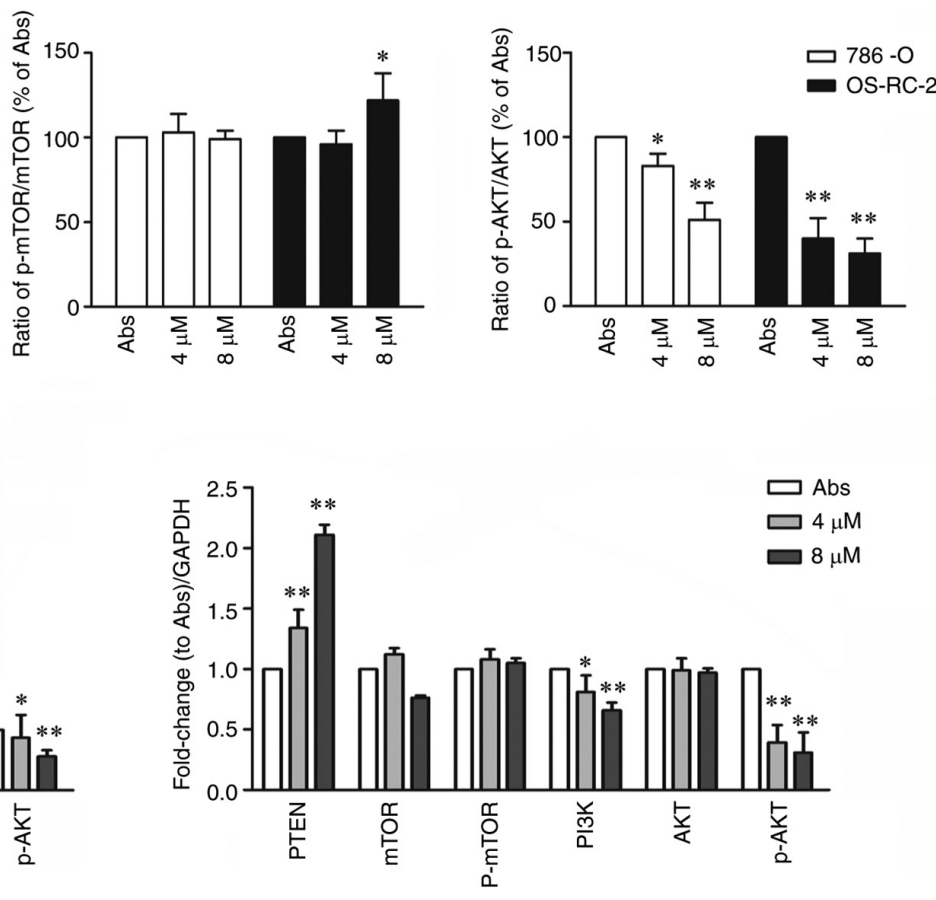

Figure 5. Naringenin inhibits renal cell carcinoma progression via activation of the PTEN/PI3K/AKT signaling pathway. Western blot analysis of PTEN, mTOR, p-mTOR, PI3K, AKT and p-AKT expression in 786-O and OS-RC-2 cells. Data are presented as the mean \pm SD. ${ }^{*} \mathrm{P}<0.05,{ }^{* *} \mathrm{P}<0.01 \mathrm{vs}$. Abs. Abs, absolute ethanol; p-, phosphorylated.

\section{Discussion}

$\mathrm{RCC}$ is one of the primary causes of cancer-associated death, accounting for $3 \%$ of all cancers in women and $5 \%$ in men (18). In the urinary system, RCC is the third largest malignant cancer (18). There are numerous management options, but it remains incurable. Compared with synthetic drugs, treatment with natural products have fewer side effects, while exhibiting favorable outcomes (13). Although other studies have reported that several natural products, such as Epigallocatechin Gallate (19), quercetin (20), englerin A (21), honokiol (22), curcumin (23) and resveratrol (24) have shown beneficial results in preclinical studies of RCC, the research on the mechanism of the therapeutic activities of natural products on RCC is remains limited. The present study examined the antitumor effects of natural products on RCC.

In the present study, sophoricoside, aucubin, notoginsenoside R1 and ginsenoside Rg1 did not exhibit cytotoxic effects. Through consulting the literature, the primary therapeutic properties of sophoricoside $(25,26)$, aucubin $(27)$ and notoginsenoside R1 (28) were found to be analgesic, anti-inflammatory, anti-viral and anti-oxidative. Up to date findings demonstrate that aucubin possesses hypolipidemic activity based on its notable anti-inflammatory and antioxidative activity, and may thus serve as a novel drug for treatment of non-alcoholic fatty liver disease (NAFLD) (29). Ginsenoside Rg1 is known for its cardioprotective effects and auxiliary antitumor effects $(30,31)$. Recently, a study suggested that ginsenoside-Rg1 is efficacious against NAFLD, and also confirmed ginsenoside-Rg1 as a potential drug for the treatment of NAFLD (32). However, their antitumor activity was shown to be very limited for treatment of RCC in the present study. It has been shown that ginsenoside Re, naringenin and allicin exhibit a concentration and species-dependent cytotoxic effect, and allicin attenuates liver oxidative stress and inflammation (33). However, ginsenoside Re and allicin exhibited very weak anti-RCC activity in the present study. Of note, certain studies have reported that naringenin, a principal flavanone enriched in citrus fruits $(34,35)$, has a variety of protective effects, including anti-oxidative (36), anti-inflammatory (37,38), anti-microbial (39) and anti-cancer activities (40). Recently, naringenin was shown to reduce hepatic lipid accumulation, highlighting its favorable therapeutic potential for treating NAFLD. Although the specific molecular mechanisms of NAFLD remain to be fully elucidated, active compounds obtained from natural products may serve as a valuable addition in the armamentarium for management of this disease (41). In addition, accumulating evidence has shown that naringenin possesses significant antitumor activity in human prostate, lung and breast cancer, amongst other types of cancer (42-46). In the present study, the $\mathrm{IC}_{50}$ of 786-O and OS-RC-2 cells treated with naringenin was $8.91 \pm 0.33$ and $7.78 \pm 2.65 \mu \mathrm{M}$, respectively. It was suggested that naringenin may serve as a promising agent to prevent or restrict tumor growth. Thus, their bioactivities and the underlying mechanisms regulated by each where assessed.

Subsequently, it was shown that naringenin significantly inhibited RCC cell proliferation by decreasing Ki67 expression. Bao et al (47) revealed that naringenin efficiently inhibited SGC-7901 gastric cancer cell proliferation by downregulating the expression of proliferating cell nuclear antigen in a timeand concentration-dependent manner. In addition, naringenin blocked cell cycle progression in the $\mathrm{G}_{2}$ phase to inhibit RCC cell proliferation by regulating expression of cell cycle proteins 

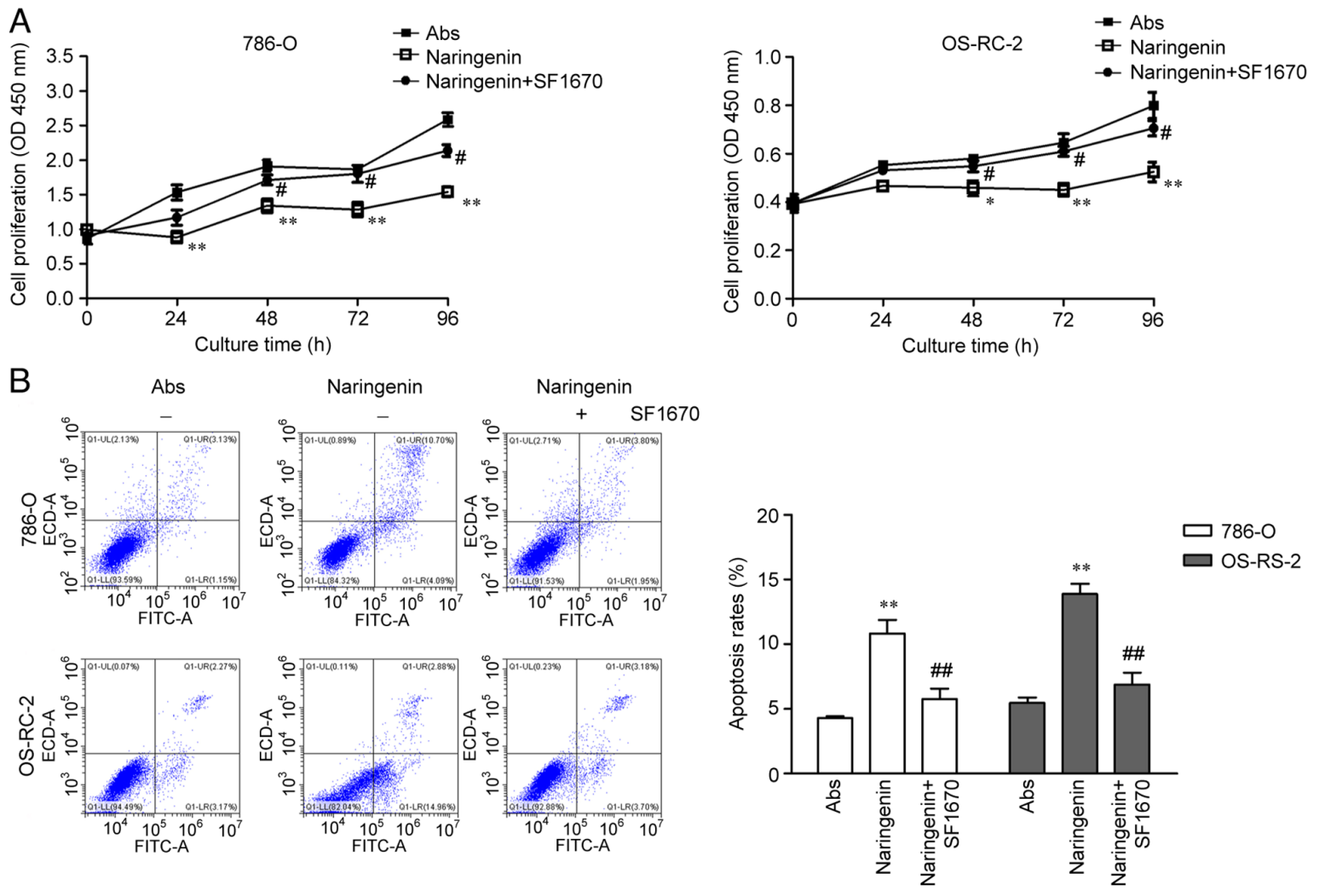

C Abs Naringenin Naringenin Abs Naringenin Naringenin
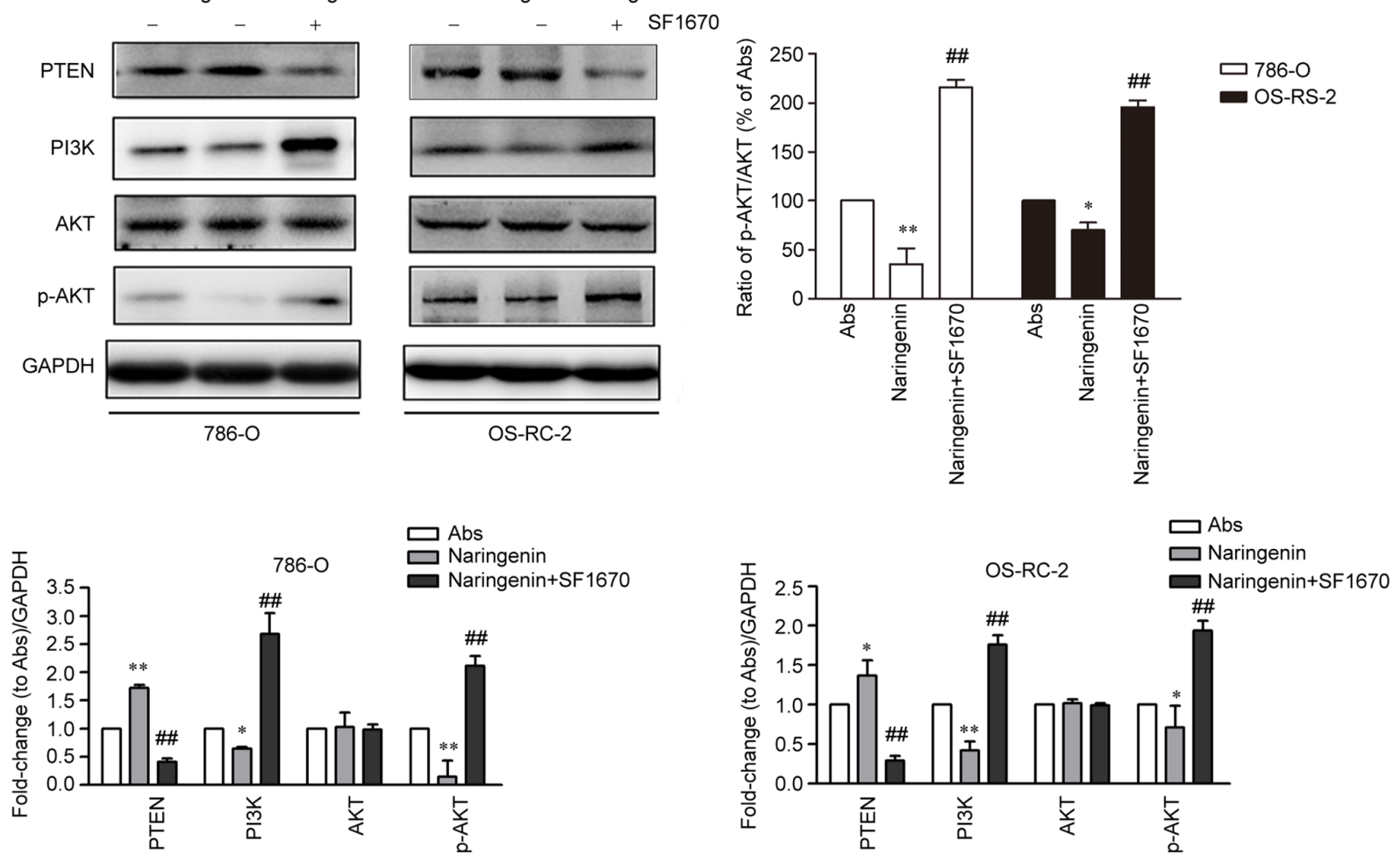

Figure 6. Regulatory effects of PTEN inhibition on renal cell carcinoma via regulation of the PI3K/AKT signaling pathway. Cells were pretreated with a PTEN inhibitor (SF1670) for $24 \mathrm{~h}$, followed by $4 \mu \mathrm{m}$ naringenin for $24 \mathrm{~h}$. (A) Proliferation was assessed using a Cell Counting Kit-8 assay. (B) Flow cytometry was used to determine the proportion of apoptotic cells. (C) Expression levels of PTEN, PI3K, AKT and p-AKT were investigated using western blotting. Data are presented as the mean $\pm \mathrm{SD}$. ${ }^{*} \mathrm{P}<0.05,{ }^{* * *} \mathrm{P}<0.01$ vs. Abs; ${ }^{*} \mathrm{P}<0.05,{ }^{\# / \prime} \mathrm{P}<0.01$ vs. naringenin. p-, phosphorylated; Abs, absolute ethanol.

in the current study. Similarly, Md et al (48), Arul et al (49) and Yan et al (50) found that naringenin induced cell cycle arrest at the $\mathrm{G}_{2}$ phase in A549 lung cancer cells, human hepatocellular carcinoma cells and during kidney injury, respectively.
Additionally, it has also been shown that naringenin exerts an anticancer effect on MDA-MB-231 breast cancer cells through arresting cell cycle progression at the $\mathrm{G}_{0} / \mathrm{G}_{1}$ phase (51). Thus, naringenin has been demonstrated to inhibit the proliferation 
A

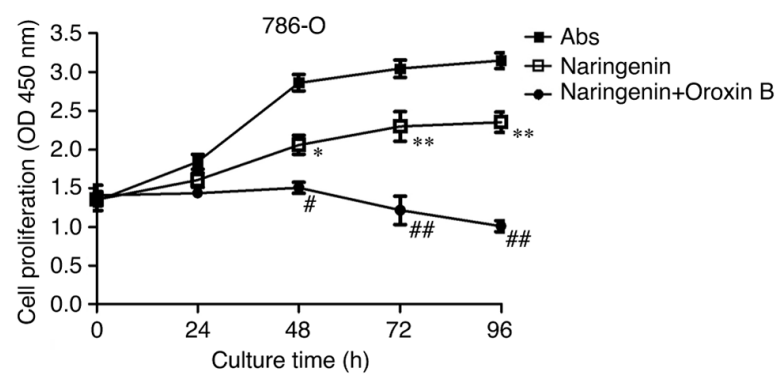

B
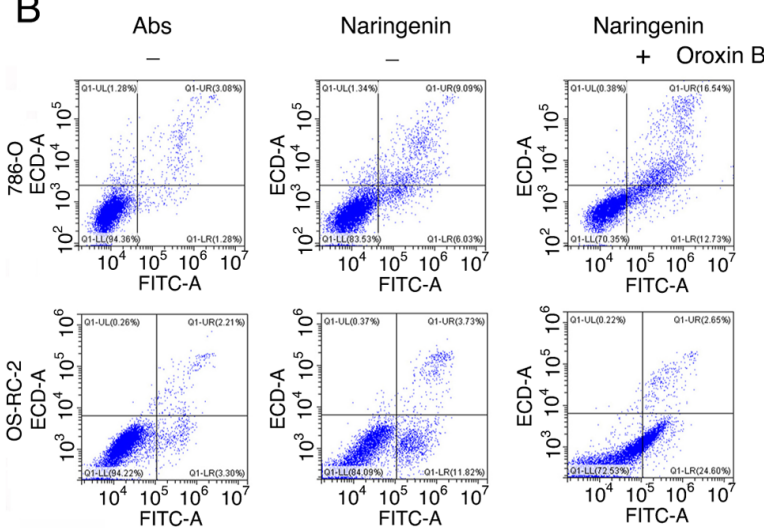

C

C Abs Naringenin Naringenin Abs Naringenin Naringenin
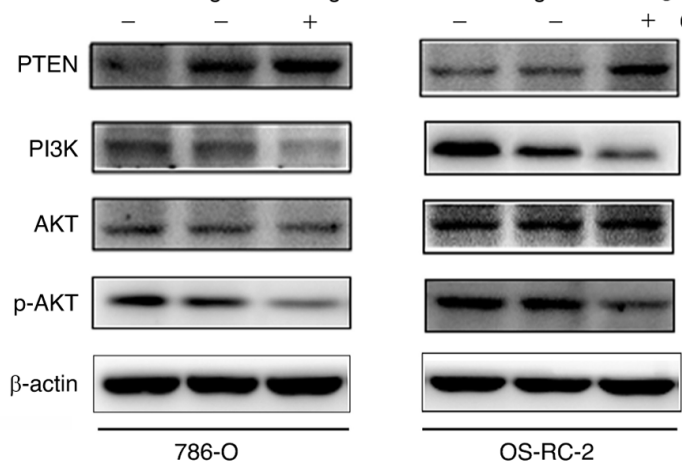

OS-RC-2

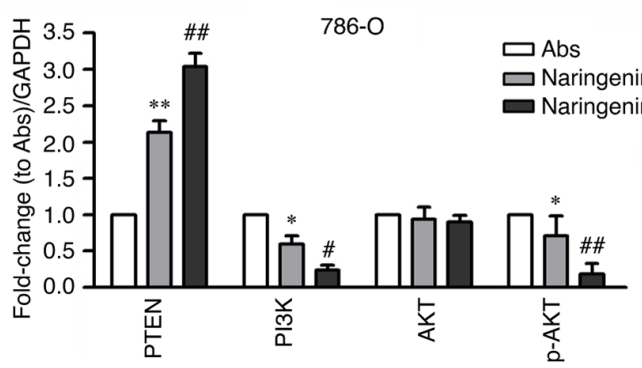

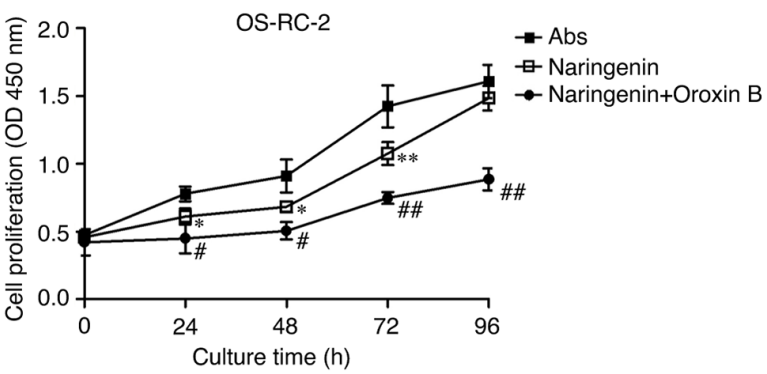
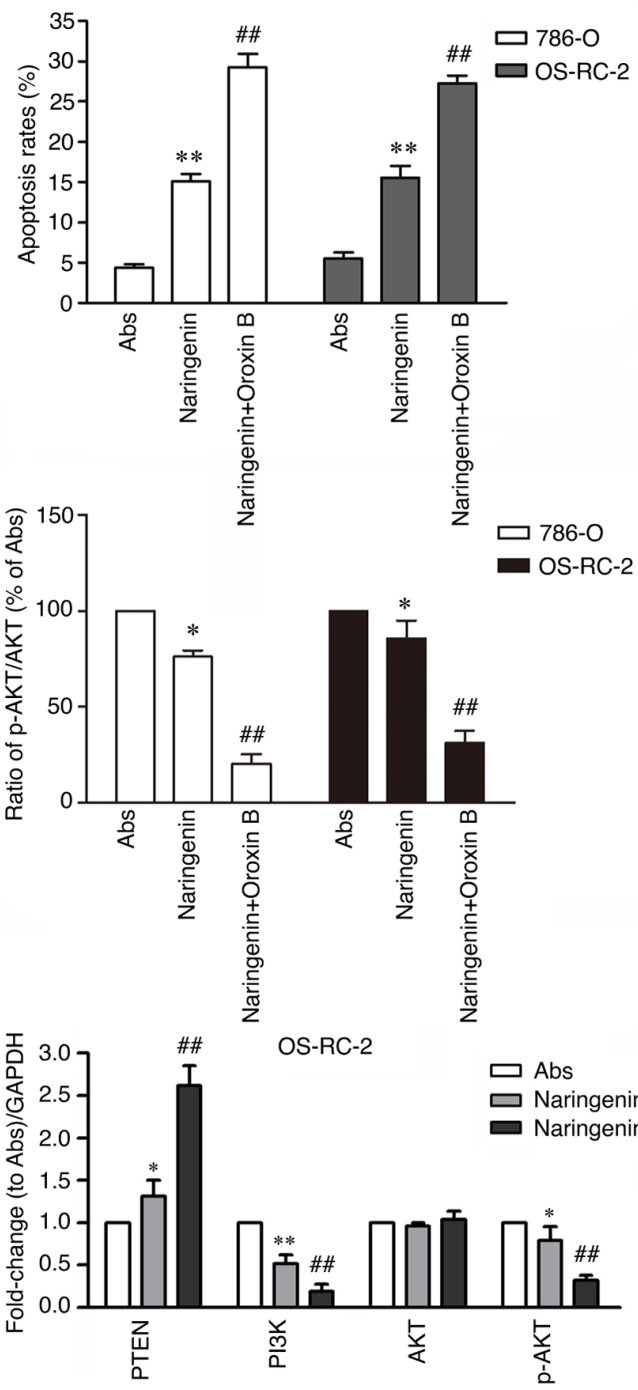

Figure 7. Regulatory effects of activation of PTEN on RCC via regulation of the PI3K/AKT signaling pathway. RCC cells were pretreated with a PTEN activator (Oroxin B), and subsequently treated with naringenin. (A) A Cell Counting Kit-8 assay was used to investigate proliferation. (B) Apoptosis was detected using flow cytometry. (C) Protein expression levels of PTEN, PI3K, AKT and p-AKT were determined using western blotting. Data are presented as the mean \pm SD. ${ }^{*} \mathrm{P}<0.05,{ }^{* *} \mathrm{P}<0.01$ vs. Abs; ${ }^{\#} \mathrm{P}<0.05,{ }^{\# \#} \mathrm{P}<0.01$ vs. naringenin. RCC, renal cell carcinoma; p-, phosphorylated; Abs, absolute ethanol.

of cancer cells by blocking cell cycle progression at different stages in different types of cancer.

Of note, in the present study naringenin significantly increased apoptosis in the 786-O and OS-RC-2 cell lines by decreasing Bcl-2 and caspase-3 expression, increasing caspase- 8 expression and altering their cellular morphology. Although, several studies have suggested that naringenin induces apoptosis via stimulation of caspase-3, caspase-9 and Bax activity, whilst inhibiting Bcl-2 activity $(46,47,52,53)$, it has also been shown that caspase- 8 mediates the transition between different cell death modes, acting as a molecular switch that regulates apoptotic, necroptotic and pyroptotic cell death pathways (54). Therefore, it is hypothesized that naringenin can induce apoptosis by regulating caspase- 8 in RCC. 
Recently, Zhou et al (55) demonstrated that naringin suppresses proliferation and induces apoptosis via repressing the PI3K/AKT pathway in thyroid cancer cells. In prostate cancercells, naringenin induced apoptotic cell death through the PI3K/AKT and MAPK signaling pathways (56). Furthermore, in the present study it was shown that PI3K and p-AKT expression levels were increased and the naringenin-induced reduction in proliferation and increase in apoptosis were attenuated following treatment with a PTEN inhibitor. However, the inhibitory effect of naringenin on proliferation and increase in apoptosis were enhanced following treatment with a PTEN activator, which increased PI3K and p-AKT expression. Therefore, these results suggested that naringenin inhibited proliferation, induced apoptosis and arrested the cell cycle progression at the $G_{2}$ phase through regulation of the PTEN/PI3K/AKT signaling pathway in RCC cells.

In conclusion, the beneficial effects of naringenin were demonstrated in the present study. The proliferation, apoptosis and cell cycle progression of RCC cells were regulated by naringenin via the modulation of the PTEN/PI3K/AKT signaling pathway. Thus, it is hypothesized that naringenin may serve as a potential anti-cancer treatment, either alone or as an adjuvant therapy. However, additional in vivo studies are required to further assess its therapeutic value.

\section{Acknowledgements}

Not applicable.

\section{Funding}

This study was supported by Zhejiang Key Laboratory of Pathophysiology (grant no. 201902), Scientific Plan of Medical and Health Planning of Zhejiang Province (grant no. 2019KY199) and the Science and Technology Projects of Agriculture and Social Development of Yinzhou District [file no. (2020) 70].

\section{Availability of data and materials}

The datasets used and/or analyzed during the current study are available from the corresponding author on reasonable request.

\section{Authors' contributions}

XW contributed to conception and design of the study, revision of important intellectual content and final approval of the version to be published. XW, ZX and ZL performed the experiments. ZX, ZL, YC, SH and YR contributed to acquisition and analysis of data. SZ and GW contributed to conception and design of the study. XW, GW and SZ confirm the authenticity of all the raw data. All authors have read and approved the final manuscript.

\section{Ethics approval and consent to participate}

Not applicable.

\section{Patient consent for publication}

Not applicable.

\section{Competing interests}

The authors declare that they have no competing interests.

\section{References}

1. Zhuang H, Meng X, Li Y, Wang X, Huang S, Liu K, Hehir M, Fang R, Jiang L, Zhou JX, et al: Cyclic AMP responsive element-binding protein promotes renal cell carcinoma proliferation probably via the expression of spindle and kinetochore-associated protein 2. Oncotarget 7: 16325-16337, 2016.

2. Siegel RL, Miller KD and Jemal A: Cancer statistics, 2020. CA Cancer J Clin 70: 7-30, 2020.

3. Haque I, Subramanian A, Huang CH, Godwin AK, Van Veldhuizen PJ, Banerjee S and Banerjee SK: The role of compounds derived from natural supplement as anticancer agents in renal cell carcinoma: A review. Int J Mol Sci 19: 107, 2017.

4. Mendiratta P, Rini BI and Ornstein MC: Emerging immunotherapy in advanced renal cell carcinoma. Urol Oncol 35: 687-693, 2017.

5. Wang X, Huang S, Xin X, Ren Y, Weng G and Wang P: The antitumor activity of umbelliferone in human renal cell carcinoma via regulation of the p110gamma catalytic subunit of PI3K $\gamma$. Acta Pharm 69: 111-119, 2019.

6. Ji HF, Li XJ and Zhang HY: Natural products and drug discovery. Can thousands of years of ancient medical knowledge lead us to new and powerful drug combinations in the fight against cancer and dementia? EMBO Rep 10: 194-200, 2009.

7. Reddy D, Kumavath R, Tan TZ, Ampasala DR and Kumar AP: Peruvoside targets apoptosis and autophagy through MAPK Wnt $/ \beta$-catenin and PI3K/AKT/mTOR signaling pathways in human cancers. Life Sci 241: 117147, 2020.

8. Krushkal J, Negi S, Yee LM, Evans JR, Grkovic T, Palmisano A, Fang J, Sankaran H, McShane LM, Zhao Y and O'Keefe BR: Molecular genomic features associated with in vitro response of the NCI-60 cancer cell line panel to natural products. Mol Oncol 15: 381-406, 2021.

9. Atanasov AG, Waltenberger B, Pferschy-Wenzig EM, Linder T, Wawrosch C, Uhrin P, Temml V, Wang L, Schwaiger S, Heiss EH, et al: Discovery and resupply of pharmacologically active plant-derived natural products: A review. Biotechnol Adv 33: 1582-1614, 2015.

10. Fang J, Wu Z, Cai C, Wang Q, Tang Y and Cheng F: Quantitative and systems pharmacology. 1 . in silico prediction of drug-target interactions of natural products enables new targeted cancer therapy. J Chem Inf Model 57: 2657-2671, 2017.

11. Ha MW, Song BR, Chung HJ and Paek SM: Design and synthesis of anti-cancer chimera molecules based on marine natural products. Mar Drugs 17: 500, 2019.

12. Czarnik AW and Keene JD: Combinatorial chemistry. Curr Biol 8: R705-R707, 1998.

13. Siddiqui M and Rajkumar SV: The high cost of cancer drugs and what we can do about it. Mayo Clin Proc 87: 935-943, 2012.

14. Kang Q, Gong J, Wang M, Wang Q, Chen F and Cheng KW: 6-C-(E-Phenylethenyl)naringenin attenuates the stemness of hepatocellular carcinoma cells by suppressing wnt/beta-catenin signaling. J Agric Food Chem 67: 13939-13947, 2019.

15. O'Brien CA, Kreso A and Jamieson CH: Cancer stem cells and self-renewal. Clin Cancer Res 16: 3113-3120, 2010.

16. Sui M, Zhang H, Di X, Chang J, Shen Y and Fan W: G2 checkpoint abrogator abates the antagonistic interaction between antimicrotubule drugs and radiation therapy. Radiother Oncol 104: 243-248, 2012.

17. Sezer ED, Oktay LM, Karadadas E, Memmedov H, Gunel NS and Sözmen E: Assessing anticancer potential of blueberry flavonoids, quercetin, kaempferol, and gentisic acid, through oxidative stress and apoptosis parameters on HCT-116 cells. J Med Food 22: 1118-1126, 2019.

18. Deleuze A, Saout J, Dugay F, Peyronnet B, Mathieu R, Verhoest G, Bensalah K, Crouzet L, Laguerre B, Belaud-Rotureau MA, et al: Immunotherapy in renal cell carcinoma: The future is now. Int J Mol Sci 21: 2532, 2020.

19. Gu B, Ding Q, Xia G and Fang Z: EGCG inhibits growth and induces apoptosis in renal cell carcinoma through TFPI-2 overexpression. Oncol Rep 21: 635-640, 2009.

20. Meng FD, Li Y, Tian X, Ma P, Sui CG, Fu LY and Jiang YH: Synergistic effects of snail and quercetin on renal cell carcinoma Caki-2 by altering AKT/mTOR/ERK1/2 signaling pathways. Int J Clin Exp Pathol 8: 6157-6168, 2015. 
21. Batova A, Altomare D, Creek KE, Naviaux RK, Wang L, Li K, Green E, Williams R, Naviaux JC, Diccianni M and Yu AL: Englerin A induces an acute inflammatory response and reveals lipid metabolism and ER stress as targetable vulnerabilities in renal cell carcinoma. PLoS One 12: e0172632, 2017.

22. Hamedani Y, Chakraborty S, Sabarwal A, Pal S, Bhowmick S and Balan M: Novel Honokiol-eluting PLGA-based scaffold effectively restricts the growth of renal cancer cells. PLoS One 15: e0243837, 2020.

23. Zhang T, Zhao L, Zhang TT, Wu W, Liu J, Wang X, Wan Y, Geng H, Sun X, Qian W and Yu D: Curcumin negatively regulates cigarette smoke-induced renal cell carcinoma epithelial-mesenchymal transition through the ERK5/AP-1 pathway. Onco Targets Ther 13: 9689-9700, 2020.

24. Dai L, Chen L, Wang W and Lin P: Resveratrol inhibits ACHN cells via regulation of histone acetylation. Pharm Biol 58: 231-238, 2020.

25. Kim BH, Chung EY, Min BK, Lee SH, Kim MK, Min KR and Kim Y: Anti-inflammatory action of legume isoflavonoid sophoricoside through inhibition on cyclooxygenase-2 activity. Planta Med 69: 474-476, 2003

26. Wu C, Luan H, Wang S, Zhang X, Wang R, Jin L, Guo P and Chen X: Modulation of lipogenesis and glucose consumption in HepG2 cells and C2C12 myotubes by sophoricoside. Molecules 18: 15624-15635, 2013

27. Yang Z, Wu QQ, Xiao Y, Duan MX, Liu C, Yuan Y, Meng YY, Liao HH and Tang QZ: Aucubin protects against myocardial infarction-induced cardiac remodeling via nNOS/NO-regulated oxidative stress. Oxid Med Cell Longev 2018: 4327901, 2018

28. Liu H, Yang J, Yang W, Hu S, Wu Y, Zhao B, Hu H and Du S: Focus on notoginsenoside R1 in metabolism and prevention against human diseases. Drug Des Devel Ther 14: 551-565, 2020

29. Shen B, Zhao C, Wang Y, Peng Y, Cheng J, Li Z, Wu L, Jin M and Feng $\mathrm{H}$ : Aucubin inhibited lipid accumulation and oxidative stress via Nrf2/HO-1 and AMPK signalling pathways. J Cell Mol Med 23: 4063-4075, 2019.

30. Qin Q, Lin N, Huang H, Zhang X, Cao X, Wang Y and Li P: Ginsenoside Rg1 ameliorates cardiac oxidative stress and inflammation in streptozotocin-induced diabetic rats. Diabetes Metab Syndr Obes 12: 1091-1103, 2019.

31. Li W, Li G, She W, Hu X and Wu X: Targeted antitumor activity of Ginsenoside (Rg1) in paclitaxel-resistant human nasopharyngeal cancer cells are mediated through activation of autophagic cell death, cell apoptosis, endogenous ROS production, S phase cell cycle arrest and inhibition of $\mathrm{m}$-TOR/PI3K/AKT signalling pathway. J BUON 24: 2056-2061, 2019

32. Hou Y, Gu D, Peng J, Jiang K, Li Z, Shi J, Yang S, Li S and Fan X: Ginsenoside Rg1 regulates liver lipid factor metabolism in NAFLD model rats. ACS Omega 5: 10878-10890, 2020.

33. Nan B, Yang C, Li L, Ye H, Yan H, Wang M and Yuan Y: Allicin alleviated acrylamide-induced NLRP3 inflammasome activation via oxidative stress and endoplasmic reticulum stress in Kupffer cells and SD rats liver. Food Chem Toxicol 148: 111937, 2021.

34. Salehi B, Fokou PVT, Sharifi-Rad M, Zucca P, Pezzani R, Martins N and Sharifi-Rad J: The therapeutic potential of naringenin: A review of clinical trials. Pharmaceuticals (Basel) 12: 11, 2019.

35. Huang B, Hu P, Hu A, Li Y, Shi Q, Huang J, Jiang Q, Xu S, Li L and $\mathrm{Wu} \mathrm{Q}$ : Naringenin attenuates carotid restenosis in rats after balloon injury through its anti-inflammation and anti-oxidative effects via the RIP1-RIP3-MLKL signaling pathway. Eur J Pharmacol 855: 167-174, 2019.

36. Chanput W, Krueyos N and Ritthiruangdej P: Anti-oxidative assays as markers for anti-inflammatory activity of flavonoids. Int Immunopharmacol 40: 170-175, 2016.

37. Pinho-Ribeiro FA, Zarpelon AC, Fattori V, Manchope MF, Mizokami SS, Casagrande R and Verri WA Jr: Naringenin reduces inflammatory pain in mice. Neuropharmacology 105: 508-519, 2016.

38. Zhang C, Zeng W, Yao Y, Xu B, Wei X, Wang L, Yin X, Barman AK, Zhang F, Zhang C, et al: Naringenin ameliorates radiation-induced lung injury by lowering IL-1beta level. J Pharmacol Exp Ther 366: 341-348, 2018.
39. Joshi R, Kulkarni YA and Wairkar S: Pharmacokinetic, pharmacodynamic and formulations aspects of Naringenin: An update. Life Sci 215: 43-56, 2018.

40. Latif AD, Gonda T, Vagvolgyi M, Kúsz N, Kulmány A, Ocsovszki I, Zomborszki ZP, Zupkó I and Hunyadi A: Synthesis and in vitro antitumor activity of naringenin oxime and oxime ether derivatives. Int J Mol Sci 20: 2184, 2019.

41. Tarantino G, Citro V and Capone D: Nonalcoholic fatty liver disease: A challenge from mechanisms to therapy. J Clin Med 9: $15,2019$.

42. Fu S, Zhang Y, Shi J, Hao D and Zhang P: Identification of gene-phenotype connectivity associated with flavanone naringenin by functional network analysis. PeerJ 7: e6611, 2019.

43. Hermawan A, Ikawati M, Jenie RI, Khumaira A, Putri H, Nurhayati IP, Angraini SM and Muflikhasari HA: Identification of potential therapeutic target of naringenin in breast cancer stem cells inhibition by bioinformatics and in vitro studies. Saudi Pharm J 29: 12-26, 2021.

44. Han KY, Chen PN, Hong MC, Hseu YC, Chen KM, Hsu LS and Chen WJ: Naringenin attenuated prostate cancer invasion via reversal of epithelial-to-mesenchymal transition and inhibited uPA activity. Anticancer Res 38: 6753-6758, 2018.

45. Tan Z, Sun Y, Liu M, Xia L, Cao F, Qi Y and Song Y: Naringenin inhibits cell migration, invasion, and tumor growth by regulating circFOXM1/miR-3619-5p/SPAG5 axis in lung cancer. Cancer Biother Radiopharm 27: 1089, 2020.

46. Choi J, Lee DH, Jang H, Park SY and Seol JW: Naringenin exerts anticancer effects by inducing tumor cell death and inhibiting angiogenesis in malignant melanoma. Int J Med Sci 17: 3049-3057, 2020.

47. Bao L, Liu F, Guo HB, Li Y, Tan BB, Zhang WX and Peng YH: Naringenin inhibits proliferation, migration, and invasion as well as induces apoptosis of gastric cancer SGC7901 cell line by downregulation of AKT pathway. Tumour Biol 37: 11365-11374, 2016.

48. Md S, Alhakamy NA, Aldawsari HM, Husain M, Kotta S, Abdullah ST, Fahmy UA, Alfaleh MA and Asfour HZ: Formulation design, statistical optimization, and in vitro evaluation of a naringenin nanoemulsion to enhance apoptotic activity in A549 lung cancer cells. Pharmaceuticals (Basel) 13: 152, 2020

49. Arul D and Subramanian P: Naringenin (citrus flavonone) induces growth inhibition, cell cycle arrest and apoptosis in human hepatocellular carcinoma cells. Pathol Oncol Res 19: 763-770, 2013.

50. Yan N, Wen L, Peng R, Li H, Liu H, Peng H, Sun Y, Wu T, Chen L, Duan Q, et al: Naringenin ameliorated kidney injury through Let-7a/TGFBR1 signaling in diabetic nephropathy. J Diabetes Res 2016: 8738760, 2016.

51. Zhao Z, Jin G, Ge Y and Guo Z: Naringenin inhibits migration of breast cancer cells via inflammatory and apoptosis cell signaling pathways. Inflammopharmacology 27: 1021-1036, 2019.

52. Wang R, Wang J, Dong T, Shen J, Gao X and Zhou J: Naringenin has a chemoprotective effect in MDA-MB-231 breast cancer cells via inhibition of caspase-3 and -9 activities. Oncol Lett 17: 1217-1222, 2019.

53. Wang Y, Liu Z, Liu Q, Han Y, Zang Y, Zhang H, Du X, Qin T and $\mathrm{Wu} \mathrm{Y}$ : Honokiol suppressed pancreatic cancer progression via miR-101/Mcl-1 axis. Cancer Manag Res 12: 5243-5254, 2020.

54. Newton K, Wickliffe KE, Maltzman A, Dugger DL, Reja R, Zhang Y, Roose-Girma M, Modrusan Z, Sagolla MS, Webster JD and Dixit VM: Activity of caspase-8 determines plasticity between cell death pathways. Nature 575: 679-682, 2019.

55. Zhou J, Xia L and Zhang Y: Naringin inhibits thyroid cancer cell proliferation and induces cell apoptosis through repressing PI3K/AKT pathway. Pathol Res Pract 215: 152707, 2019.

56. Lim W, Park S, Bazer FW and Song G: Naringenin-induced apoptotic cell death in prostate cancer cells is mediated via the PI3K/AKT and MAPK signaling pathways. J Cell Biochem 118: 1118-1131, 2017

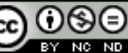

This work is licensed under a Creative Commons Attribution-NonCommercial-NoDerivatives 4.0 International (CC BY-NC-ND 4.0) License. 